\title{
Towards a probabilistic model for predicting ship besetting in ice in Arctic waters
}

\author{
Shanshan Fu a,b,c , Di Zhang a,b,*, Jakub Montewka ${ }^{\text {de, }, f}$, Xinping Yan ${ }^{\text {a,b }}$, Enrico Zio ${ }^{\text {c,g }}$ \\ a National Engineering Research Center for Water Transport Safety, Wuhan, China \\ b Intelligent Transport Systems Research Center, Wuhan University of Technology, Wuhan, China \\ c Chair on Systems Science and the Energetic Challenge (Foundation, EDF), Centrale-Supélec, Université Paris-Saclay, France \\ d Aalto University, Department of Applied Mechanics, Research Group of Maritime Risk and Safety, Espoo, Finland \\ e Finnish Geospatial Research Institute, Masala, Finland \\ f Gdynia Maritime University, Faculty of Navigation, Department of Transport and Logistics, 81-225 Gdynia, Poland Poland \\ g Department of Energy, Politecnico di Milano, Milano, Italy
}

\begin{abstract}
Recently, the melting of sea ice due to global warming has made it possible for merchant ships to navigate through Arctic Waters. However, Arctic Marine Transportation System remains a very demanding, dynamic and complex system due to challenging hydro-meteorological conditions, poorly charted waters and remoteness of the area resulting in lack of appropriate response capacity in case of emergency. In order to ensure a proper safety level for operations such as ship transit within the area, a risk analysis should be carried out, where the relevant factors pertaining to a given operation are defined and organized in a model. Such a model can assist onshore managers or ships' crews in planning and conducting an actual sea passage through Arctic waters. However, research in this domain is scarce, mainly due to lack of data. In this paper, we demonstrate the use of a dataset and expert judgment to determine the risk influencing factors and develop a probabilistic model for a ship besetting in ice along the Northeast Passage. For that purpose, we adopt Bayesian belief Networks (BBNs), due to their predominant feature of reasoning under uncertainty and their ability to accommodate data from various sources. The obtained BBN model has been validated showing good agreement with available state-of-the-art models, and providing good understanding of the analyzed phenomena.
\end{abstract}

Key words: ship performance in Arctic waters, ship stuck in ice, probabilistic risk assessment, Bayesian belief networks

\section{Introduction}

The melting of the Arctic sea ice due to global warming has enabled voyages through Arctic waters [1-3]. With the opening of Arctic waters, the frontier of exploration of hydrocarbon resources can be pushed significantly northern, and also the existing trading routes between Europe and the Far East may change. The Northeast Passage offers a shorter and faster transit compared with the traditional Suez Canal or Panama Canal [4,5]. According to statistics from the Northern Sea Route (NSR) information office [6], there were 211 transits between 2011 and 2014, as shown in Fig. 1. The main ship types were oil and chemical tankers, as well as general cargo ships. Among these, two oil tankers "Marilee" and "Palva" crossed this route eastbound en-route to Incheon and Daesan ports in Korea, respectively, during the summer of 2012 [6]. Additionally, a general cargo ship "Yong Sheng" successfully transited the route westbound from Taicang in China to Rotterdam in Netherlands in the summer of 2013 [6,7]. 


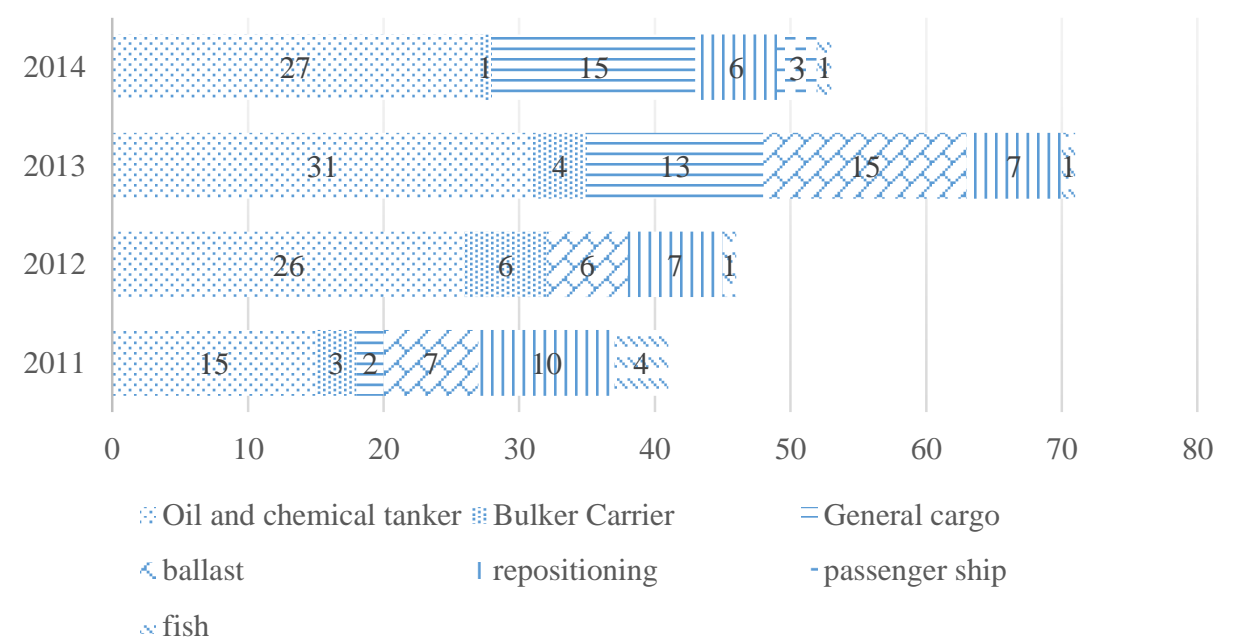

Fig. 1. Transit in NSR from 2011 to 2014.

Due to these new routes that are emerging, the safety of shipping and other maritime operations in Arctic waters has become of global interest. As a result, an international code for ships operating in polar waters (the Polar Code) was adopted by the International Maritime Organization in 2014, during its 94th Maritime Safety Committee (MSC) meeting [8], following a decade of discussion and deliberation. The Polar Code is expected to enter into force on 1 January 2017, to address all relevant issues pertaining to ships operating in waters surrounding the two poles, such as their design, construction, equipment, operation, training, search and rescue, and environmental protection, see for example [8]. Potential navigational hazards in Arctic waters have also been provided in this regulation, such as ice, low temperature, high latitude, remoteness and possible lack of accurate and complete hydrographic data and information, lack of suitable emergency response equipment and rapidly changing and severe weather conditions. However, the code is flexible in relation to determining the influencing factors for a specific operation, or the appropriate modeling techniques for risk assessment. One of the major operational risks for ice navigation is associated with a ship becoming beset in ice [9-14], which may result in a myriad of consequences, including, but not limited to, uncontrolled ship drift, listing, hull damages including plate breaching, and sinking in the worst case. In case the risk of a ship stuck in ice is acceptable, the operations can be safely carried out. However, if the risk goes beyond the unacceptable level, the safe operations may be at stake, therefore efficient risk control options (RCOs) may be required to ensure safety. In order to quantify the risk, an appropriate risk model of a ship stuck in ice during Arctic transit is required. Since the risk models are developed for a specific purpose and usually have limited scope, there exists no risk model for a ship stuck in Arctic ice accident. Thus, the main aim of this paper is to develop such a model, utilizing experts' knowledge, available historical environmental data and navigational data obtained from a merchant voyage in Arctic waters.

A large body of knowledge exists on ship performance in ice-covered waters, which can be helpful in determining the relevant factors for the risk model presented here. For instance, the work on ice-induced load on ship hull can provide insight in the relationship between the parameters of ice cover and extent of damage that may be expected, see for example $[15,16]$. Likewise, an approach to determine the safe speed in Arctic ice, which will not result in hull damage, based on observed ice feature is proposed by Transport Canada [17] called "egg regulations", a structural equation modelling is proposed for determining the dependence relationships of the risk influencing factors (RIFs) in Arctic Marine Transportation System [18]. Moreover, a few event-oriented models have been proposed in recent years to quantify the major navigational risks in ice-covered waters. Khan et al [19] proposed a transportation risk analysis framework for Arctic waters by using a BN method. Kum et al [20] used a 
fuzzy fault tree method considering some causal risk factors in human and management aspects with reference to collision and grounding accidents in Arctic waters. Marken et al [21] conducted a delay risk analysis of ship sailing in the NSR by using a traditional Bow-tie diagram, integrated by fault tree and ET analyses. Afenyo et al [22] discussed the transport of oil spills in ice-covered water. Montewka et al [13,14] analyzed ship performance in dynamic ice and predicted the probability of a ship stuck in ice in the Northern Baltic Sea. Valdez Banda et al $[23,24]$ conducted a risk assessment for winter navigation systems in the Northern Baltic Sea, providing insights into the relevant risk factors. Goerlandt et al [25] carried out an analysis of winter operations in the Northern Baltic Sea involving icebreakers and assisted ships, pointing to various relationships between the ice feature and operational characteristics. Various RIFs pertaining to ship performance and environment are considered in these models; however, they are to a large extent developed with the use of subjective judgment as a main source of background knowledge, and the uncertainty associated with these models is rarely discussed. Furthermore, the dependence and interdependence relationships of RIFs have not been considered in depth neither properly illustrated in these models. Since lack of understanding and limited information are the major hazards [8] and primary causes of epistemic uncertainties [26,27], there is a need to adopt appropriate modeling techniques that allow for inference in the presence of uncertainty.

To address the main challenges related to modeling risks of a ship stuck in ice during transit along Arctic waters, we combine the expert knowledge elicitation with a dataset from voyages through the NSR. This dataset includes ship performance data and associated surrounding environmental data, including wind speed, air temperature, visibility, sea temperature, ice concentration, ice thickness, wave height, ship speed and engine. The BBN can combine data obtained from various sources, which is required here, since the dataset recorded during ship transit does not cover the whole modeling space. Since the dataset is not complete, covering specific conditions only, we elicited knowledge from five experts and incorporated this into the BBN model to fill the gap.

The primary feature of the resulting risk model is that it enables to measure the effect of combinations of various input risk influencing factors (variables) on the output called risk indicator. The latter is the probability of a ship stuck in ice. Indeed, by backward propagation of the evidence in the BBN, one can determine the most probable combination of the input variables required to achieve a predefined output - the probability of a ship stuck in ice. The risk model is also validated, with the use of a framework suitable for models that are elicited from experts or which are based on scarce and limited datasets. The results of the validation show strong agreement with the state-of-the-art models available and a general understanding of the analyzed phenomena. The model provides an insight into the combined effect of risk factors on the probability of a ship stuck in ice, and it properly distinguishes between different scenarios. In principle, it can assist onshore managers or the ship's crew in planning and conducting an actual sea passage through Arctic waters.

The remaining of the paper is organized as follows. Section 2 introduces the adopted methodology. Section 3 presents risk influencing factors (RIFs), the adopted case and correspond data information used for the development of the BBN model. The developed BBN model and the obtained results are shown in Section 4, model validation is discussed in Section 5, and discussed in section 6. Section 7 concludes the research findings.

\section{Bayesian belief networks}

As a modeling technique, a BBN is a specific type of quantitative causal model structured based on Bayes' theorem and composed of a directed acyclic graph and a set of probability statements, which is used to model uncertainty in a domain or a system under consideration [28]. It features several abilities that fully justify its use for our purpose, including the ability to make statistical inference including those with limited data [29], the ability to make use of multiple sources of data or information to describe conditional probability distributions or conditional probability tables (CPTs) for various variables in the systems, the ability to analyze inherent causal and complex 
dependencies among systematic indicators [30,31] and the ability of updating the prior probability of some unknown variable when some evidence describing that variable exists [32]. Due to these advantages, BBN has been widely used to develop risk models for maritime transportation systems [33-35], to facilitate decision making under the realm of uncertainty for critical infrastructures [36,37] and to provide tools for safety management [38]. Moreover, the BBN has been proposed by the International Maritime Organization, as a powerful tool for risk assessment [39].

Generally, a BBN modelling consists three steps: BBN structure, BBN quantification and Inference in a BBN [31], which are described in the following subsections.

\subsection{BBN structure}

A BBN is a probabilistic graphical model that represents a set of random variables and their conditional dependence and independence relationships via a directed acyclic graph (DAG). The DAG consists of nodes and directed arcs. Each node represents a single variable in the system and has a finite set of mutually exclusive states. For a discrete BBN, each node has a finite number of possible states that can be either binary (yes/no, true/false, success/failure) or multiple states. Directed arcs are used to represent the causal influences between nodes, with the arrowhead indicating the direction of causality.

The development of a causal BBN structure is to identify the variables to be included as nodes in the model, and then identify the relationships (arcs) between the variables. The variables (nodes) in a BBN are determined by the aim of the study, which can be selected in terms of relevant studies and expert knowledge. For the relationships between the variables, causality is one of the main paradigms for a given pair of variables. Correlation analysis can be used to explore pairwise relationships between various variables when historical or observation data are available for these variables, and the results of this analysis can assist in determining the complex structure of the causal BBN model.

To determine correlations in the set of analyzed data, Pearson, Kendall's tau_b and Spearman correlation coefficients have been adopted to describe the correlation relationship between two variables [40]. To measure the degree of linear dependence between two variables, the Pearson product-moment correlation coefficient (PMCC) is a widely-used correlation metric, estimated as follows:

$$
r_{P M C C}=\frac{\sum_{i=1}^{n}\left(X_{i}-\bar{X}\right)\left(Y_{i}-\bar{Y}\right)}{\sqrt{\sum_{i=1}^{n}\left(X_{i}-\bar{X}\right)^{2}} \sqrt{\sum_{i=1}^{n}\left(Y_{i}-\bar{Y}\right)^{2}}},
$$

where $\mathrm{X}$ and $\mathrm{Y}$ are two variables with $\mathrm{n}$ sets of sample data, as $\left\{\left(X_{i}, Y_{i}\right), i=1,2, \ldots, n\right\}, \bar{X}$ and $\bar{Y}$ are the means of the sample data $\mathrm{X}$ and $\mathrm{Y}$, respectively. The coefficient $r_{P M C C}$ takes a value in the range [-1, 1], where 1 represents total positive correlation, 0 represents no correlation, and -1 represents total negative correlation.

A significance test is also conducted to justify the belief degree of the dependence between the sample data, which is calculated using the following equation.

$$
t^{*}=r \sqrt{\frac{n-2}{1-r^{2}}}
$$

where $t_{\alpha / 2}$ is the $100(1-\alpha)$ percentile of the Student $t$ distribution with $n-1$ degrees of freedom. If $\left|t^{*}\right|>t_{\alpha / 2}$, this indicates that the correlation of the sample data $\mathrm{X}$ and $\mathrm{Y}$ is significant at level $\alpha$; for example, if $\alpha$ is set at 0.01 or 0.05 , it corresponds to a belief degree of the results of $99 \%$ or $95 \%$, respectively.

It should be clarified that correlation analysis can only assist in exploring dependence relationships between variables [41,42], the direction of arcs in a BBN model should be further determined by expert knowledge or factor analysis (a statistical method that data are required for learning hidden variables and relationships in BBNs [43]). Due to lack of accurate and complete data and information in Arctic Marine Transportation System [8], the support of expert knowledge is also required for the variables without sufficient data or information for determining the 
direction of arcs.

\subsection{BBN quantification}

On the basis of BBN structure modelling, all relationships among BBN nodes are indicated by directed arcs, each node is assigned a marginal probability tables or conditional probability tables (CPT) to express the strength of the relationships between the variables in the systems. These CPTs contain all known information concerning the states of the variables based on both available data and expert opinion.

From a mathematical viewpoint, let $\mathrm{V}$ be a set of variables (RIFs) $\mathrm{V}=\left\{x_{1}, x_{2}, \ldots, x_{n}\right\}$ and $\mathrm{P}$ be a set of conditional probability distributions of $\mathrm{V}$. Then, the conditional probability distributions $\mathrm{P}(\mathrm{V})$ can be calculated as:

$$
\mathrm{P}(\mathrm{V})=\prod_{X \in V} P(X \mid \text { parents }(X)),
$$

where parents $(X)$ represents all variables upon which $X$ is directly conditioned. The direction of links between variables signifies the parent-child relationship, with an arrowhead pointing towards a child. BBN encodes the joint probability distribution governing a set of variables by determining a set of CPTs. Each variable is allocated with a CPT, which contains the probability values of that variable given the values of its parents in the graph. A CPT describes all conditional probabilities for all possible combinations of the states of the parent variables.

The conditional posterior probability distribution and the joint probability distribution can be computed as:

$$
\begin{aligned}
& \mathrm{P}\left(X_{i}=x_{i} \mid X_{j}=x_{i}\right)=\frac{P\left(X_{i}=x_{i}\right) P\left(X_{j}=x_{j} \mid X_{i}=x_{i}\right)}{p\left(X_{j}=x_{i}\right)}, \\
& P\left(X_{i}=x_{i}, X_{j}=x_{j}\right)=\mathrm{P}\left(X_{i}=x_{i}\right) \mathrm{P}\left(X_{j}=x_{j} \mid X_{i}=x_{i}\right) .
\end{aligned}
$$

CPTs can be populated by using multiple sources of data, including expert knowledge, observation data or combination of both. For a $m$-states node with $n$ parents and $l$-states for each parent nodes, the CPT will contain $m * n^{l}$ columns, and each column in the CPT must sum to 1 . Many works in applying BBNs use only Boolean variables (binary nodes) to reduce the complexity of the CPTs [44,45].

\subsection{Inference in a $B B N$}

Once a CPT is set to each node, the prior BBN model is complete (fully quantified) and capable to make inference. The quantified BBN represents the prior knowledge. The BBN provides a coherent method of mathematically expressing the changes in uncertainty when new knowledge about the nodes are gained. Within conditional probability distributions in a BBN, different variables are combined and their values can be updated whenever new information is obtained as additional data.

An analyst can provide new information or knowledge by setting evidences about one or several nodes when new evidence becomes available. This information is automatically propagated through the network to produce updated probabilities for all nodes in the BBN model and examine the impact on the remaining nodes in the BBN. These updated posterior probabilities are generated results of both prior information and new evidence after entering evidence to improve the states of knowledge. This process can be repeated as long as new evidence becomes available.

\section{Risk influencing factors of Arctic transportation marine system}

A case study of a trip of Yong Sheng vessel, via the NEP from Taicang port in China to Rotterdam port in Netherlands, is used to demonstrate the usability of the onboard measurement towards the estimation of the probability of ship stuck in ice. We chose this case study because this trip is representative with a typical ship type 
and size in the summer voyage in Arctic waters. Moreover, the ship navigation data (such as ship speed and engine power) and surrounding environmental data were recorded in this trip so as to support navigational risk analysis.

\subsection{Description of risk influencing factors in Arctic waters}

Safe navigation across the Arctic waters may be influenced by various characteristics of environment conditions, human factors, other vessels, navigation aids as well as ship herself [43]. The crew of merchant ships experience challenging ice conditions, low temperature, inadequate seamarks, remoteness from habituated areas along with the increased uncertainty of navigation equipment due to high latitude effects [8, 18-20]. The harsh environment has a great influence on performance of human and technical systems of a ship $[13,14,46]$.

This study concentrates on the RIFs pertaining to ship performance and environment. Corresponding RIFs are illustrated in Fig. 2. Organizational and human related factors are beyond the scope of this study.

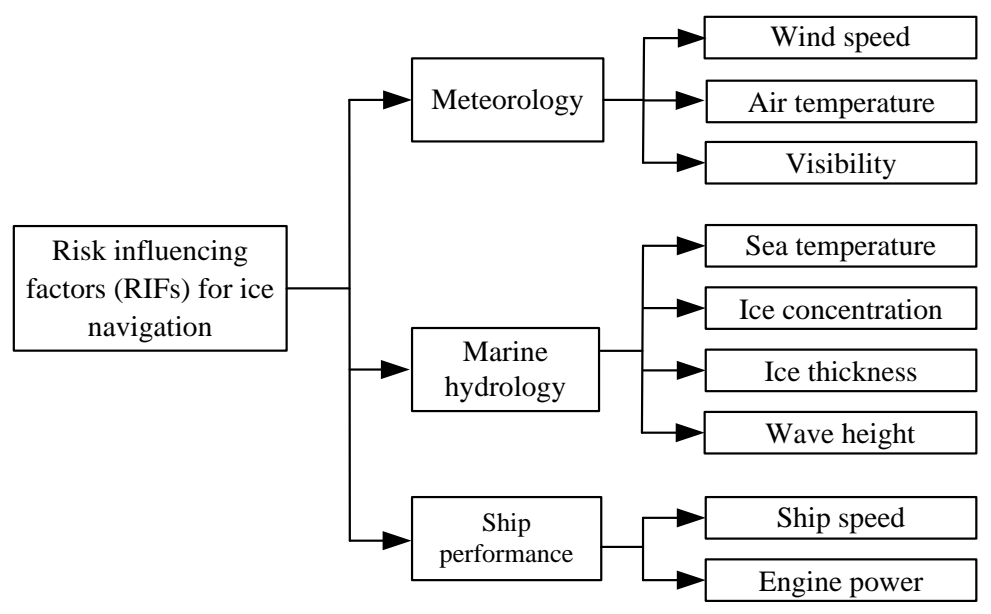

Fig. 2. Proposed risk influencing factors (RIFs) classification for use in risk analysis in the Arctic marine transportation system. The RIF hierarchy provides a common-based framework that can be expanded to deeper level in the future.

The selection of RIFs presented in Fig. 2 is based on the relevant studies [8,13,14,17-24,46-49] and extensive discussions with experts in this domain. The RIFs for ice navigation is set in the top level as the aim of the study. The parameters in level 2 are set to be meteorology, marine hydrology and ship performance. Each parameter in level 2 is investigated based on its associated factors given in level 3.

First, as for parameters from meteorology, wind speed has relations to ship operations about ship's navigation speed and associated angles controls [13,14,24]. Low temperature (air temperature) may lead to freeze of cold air, which frosts deck as well as associated equipment on board [8,46-49]. Moreover, visibility is a parameter to express impacts from fogs, whiteout and aurora borealis in NSR area [46,47].

Second, as for elements from marine hydrology, sea ice is a key attribute to ice navigation [8,13,14,17-24,46-49], ice concentration and ice thickness are significant attributes in terms of sea ice condition [8, 13,14,17-24,46-49]; sea temperature affects the formation of sea ice, which is also a significant risk factor in ice navigation [8,47-49]; moreover, sea ice is exposed to waves, wave height is a crucial parameter that determine the operation of ships [47].

Third, as for element from ship performance, ship speed and engine power are essential factors to reflect ships performance during voyage $[13,14,18]$.

\subsection{Description of the trip}


The Yong Sheng vessel is a 1A general cargo according to the polar code [8]. It is a medium-sized ship with a dead weight tonnage (DWT) of 14357 tons, 159.95 meters long, 23.70 meters broad, with maximum draught of 8.15 meters. Its operational power is 7074 kilowatts. The main characteristics of the ship are gathered in Table 1 .

\section{Table 1}

The main characteristics of the ship used as a platform for data recording.

\begin{tabular}{cc}
\hline Name & Yong Sheng \\
\hline Type & General cargo \\
Ice class & Arc 4 (Russian ice class) \\
DWT & $14357 \mathrm{t}$ \\
Length & $159.95 \mathrm{~m}$ \\
Breadth & $23.70 \mathrm{~m}$ \\
Draught & $8.15 \mathrm{~m}$ \\
Operational power & $7074 \mathrm{kw}$ \\
\hline
\end{tabular}

The ship has entered Arctic waters on $28^{\text {th }}$ of August 2013 and sailed westwards for seven days, when she finally left the Arctic waters (Barents Sea) on the $4^{\text {th }}$ of September 2013. During her eight-day voyage, she encountered various ice conditions and recorded them. The ship was transiting Arctic waters in the middle of the sailing season, which in 2013 started on $25^{\text {th }}$ of June and ended around the end of November (see the Arctic Institute's web page for further details on the trip in [6]). Since the ice conditions along the route are characterized by spatial-temporal variations (ships can take various routes, and the ice conditions will be different in the beginning of the season, in the middle or at the end of the sailing season), the data collected during the trip reflect the conditions along the specific route taken in the specific time. During her entire voyage in Arctic waters, whose track is depicted in Fig. 2, the ship was escorted by Russian icebreaker "50 Let Pobedy" from 28th of August morning 14:37 to 2nd of September 14:50 in an escorting operation to break an ice channel that is, then, followed by the assisted icebreaker, at a recommended distance [23]. In the rest of the time the ship travelled unassisted.

The crews of Yong Sheng on duty recorded the measurement values of ship performance and surrounding environment once per hour. The case study presented here is based on the records of ship performance and the surrounding environment while within NSR and Barents Sea, meaning that only such stage of the journey within the Arctic is considered. In Fig. 3, the trajectory of Yong Sheng along Arctic waters is overlaid on a map, and the track followed is marked with purple circles. 


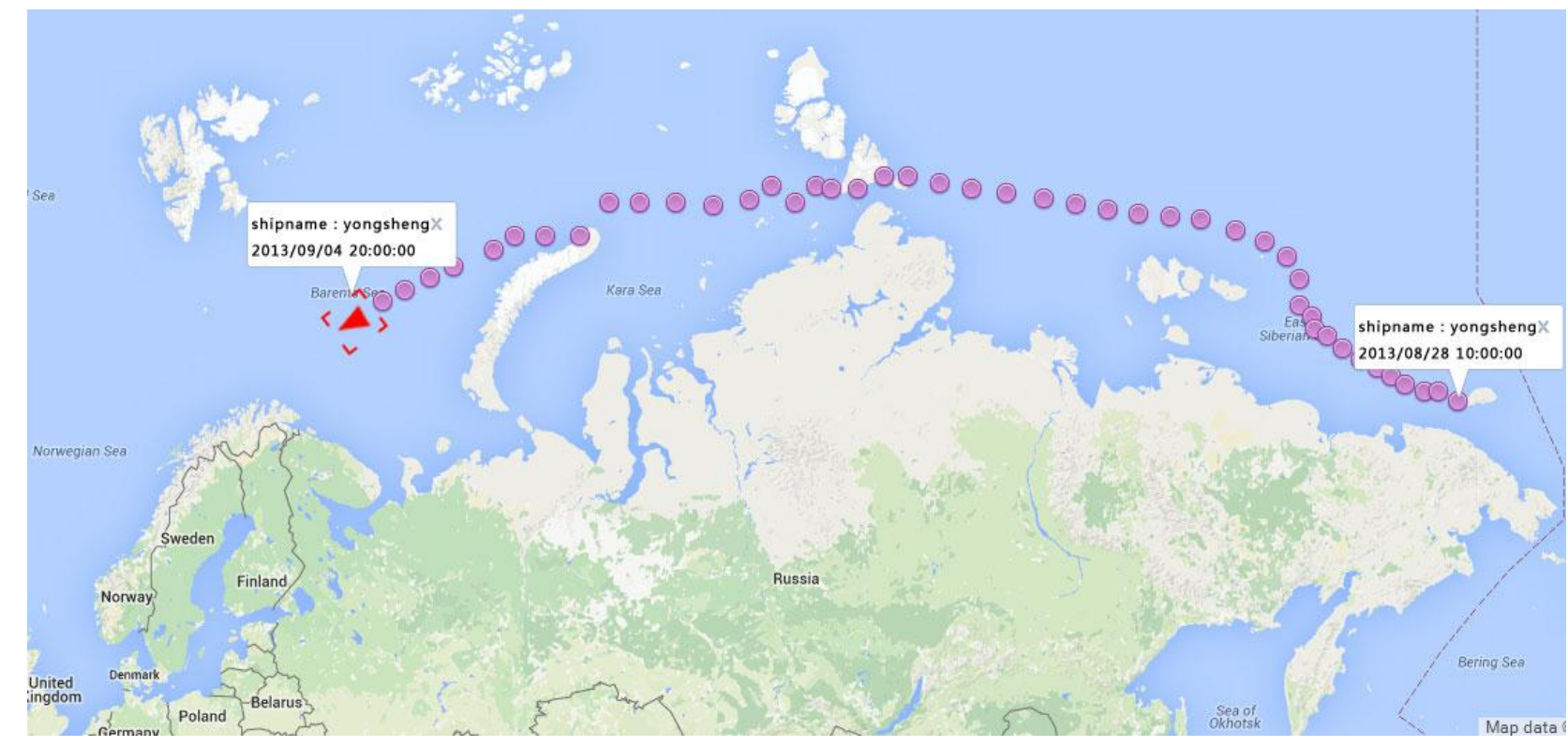

Fig. 3. The track of the analyzed ship along Arctic waters. The data are provided by the China Ocean Shipping (Group) Company (COSCO)

\subsection{Data sources}

In developing the BBN model, two sources of data were selected: navigation dataset from $\mathrm{m} / \mathrm{s}$ Yong Sheng during NEP voyage and expert knowledge in this domain. The navigation dataset source was selected because it contained detailed information about the majority of the identified RIFs in section 3.2 that influence the probability of ship stuck in ice along Arctic waters. Moreover, this dataset was specifically to capture challenging environmental conditions and the performance of ship in Arctic waters.

The database contains 179 rows of data uniformly distributed in time (once per hour along Arctic waters). Each row in the database comprises of 10 columns representing the following parameters - including three response variables:

- ship speed (kn) - response variable,

- ship stuck in ice [yes/no] - response variable,

- engine power $(\%)$ - response variable,

- wind speed $(\mathrm{m} / \mathrm{s})$,

- air temperature $(\mathrm{C})$,

- visibility (level),

- sea temperature (C),

- ice concentration (\%),

- ice thickness (level) and

- wave height (deg).

The majority of the above parameters (except the response variable ship stuck in ice) were acquired by specific measurement of data during the voyage. Visibility and wave parameters were recorded based on a meteorological degree according to the visibility scale [50] and the Douglas Sea scale [51]. The ice thickness parameter was estimated to be one of two discrete states: below 0.5 meter or above 0.5 meter. The ship stuck in ice parameter was derived from the observation of the crew on board. The recorded engine power and the data related to the ice 
concentration parameters contain significant variability and the environmental conditions strongly affect the ship's speed, as depicted in Fig. 4. Therein, on time step 114 the ship was considered to be stuck in ice according to the description of the crews on duty, in a harsh sea ice with $80 \%$ ice concentration and high ice thickness. The ship broke the harsh sea ice with icebreaker assistance, and during the next recording time instant, the speed increased to $6.4 \mathrm{kn}$.

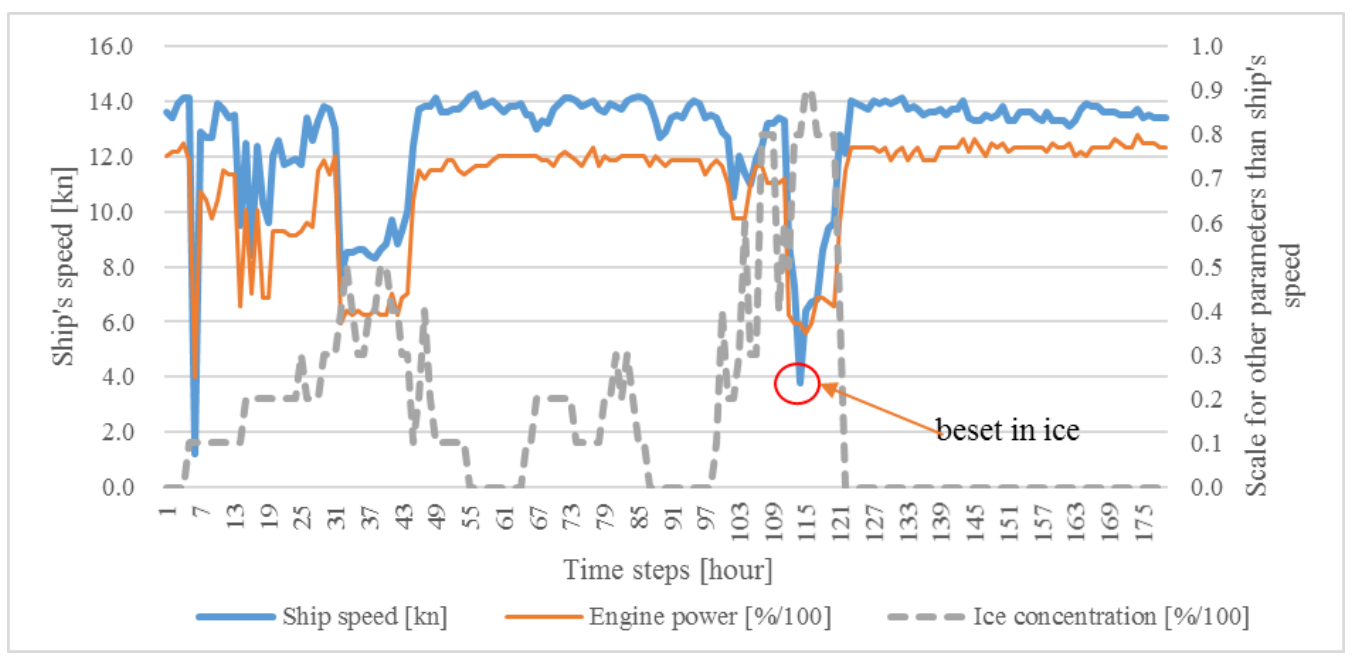

Fig. 4. Time series of ship speed, engine and ice concentration parameters in the trip.

Another source of data, experts in domain, consists of five experts in the field - two master mariners and three senior researchers, whose details are as follows:

- Expert A: A senior captain with more than 15-years navigation experience in ice-covered waters from the Polar Research Institute of China.

- Expert B: A captain with more than 15-years navigation experience in open-seas and ice-covered waters from the China Ocean Shipping (Group) Company (COSCO) (a captain of m/s Sheng Yong).

- Expert C: A professor engaged in maritime research for more than 20 years from School of Navigation of Wuhan University of Technology.

- Expert D: An associate professor engaged in maritime research for more than 10 years from Shanghai Maritime University, also engaged as a second officer onboard.

- Expert E: An associate professor engaged in maritime research for more than 5 years from the National Engineering Research Center for Water Transport Safety and Wuhan University of Technology.

\section{Modelling}

This section presents a BBN model that was developed with the use of the two sources of data discussed in section 3.3. The model that is developed demonstrates the applicability of the BBN to the prediction of ship performance. The latter is expressed in terms of attainable ship speed and the probability of besetting in ice, in the Arctic waters.

\subsection{Model nodes}

The scope of the current model was guided by the level of resolution that the current data supports. Ideally, each of RIF form the hierarchy would be represented as a single node in the model. However, a purely data-driven model will not capture all the instances of all the important variables that influence ship performance, [14]. To 
cover the most of the analyzed space, additional data is necessary. The set of nodes used in the model was developed in terms of the RIF hierarchy - see Fig. 2 - and is presented in Table 2.

The final set of nodes in the model contains the nine parameters that determine the ship performance in Arctic waters and a response variable - "ship stuck in ice". The nodes were discretized into several states, adopting classification criteria of proposed by the MSC [52] and relevant studies [13,14], and driven by the variation in the available data. Specifically, engine power, air temperature, low visibility, sea temperature, ice thickness and ship stuck in ice parameters are decomposed into two states. Ship speed, wind speed and wave height parameters are decomposed into three states. Whereas variable called ice concentration parameter is decomposed into four states. Therein, low visibility and ship stuck in ice are binary parameters that are justified by the onboard practices.

\section{Table 2}

The ten nodes used in the final causal model (left column) were developed in terms of RIF hierarchy in Fig. 2 using the available data.

\begin{tabular}{cccccc}
\hline No & Model node & State $1\left(\mathrm{~S}_{1}\right)$ & State $2\left(\mathrm{~S}_{2}\right)$ & State 3 $\left(\mathrm{S}_{3}\right)$ & State $4\left(\mathrm{~S}_{4}\right)$ \\
\hline 1 & Ship speed $(\mathrm{kn})$ & $<5$ & $5 \sim 10$ & $>10$ & \\
2 & Engine power $(\%)$ & $<50$ & $>50$ & & \\
3 & Wind speed $(\mathrm{m} / \mathrm{s})$ & $<5.5$ & $5.5 \sim 7.9$ & $>7.9$ & \\
4 & Air temperature $(\mathrm{C})$ & $<0$ & $>0$ & & \\
5 & Low visibility (m) & yes & no & & \\
6 & Sea temperature (C) & $<0$ & $>0$ & & $>70$ \\
7 & Ice concentration (\%) & 0 & $10 \sim 30$ & $40 \sim 60$ & \\
8 & Ice thickness (m) & $<0.5$ & $>0.5$ & & \\
9 & Wave height (m) & $<0.5$ & $0.5 \sim 1.25$ & $>1.25$ & \\
10 & Ship stuck in ice & Yes & no & & \\
\hline
\end{tabular}

\subsection{Model Structure}

The model was structured based on the results of correlation analysis conducted here. The model contains ten nodes, as presented in table 2, each corresponding to a specific RIF as depicted in Fig. 2. Directed arcs were drawn between RIFs with correlation above |0.3| [32], with a causal relationship supported by expert judgment and related works $[13,14,18]$. Additional directed arcs, supported by expert judgment, were drawn from RIFs to the risk indicator (ship stuck in ice) and the BBN model is presented as Fig. 5. In this section we discuss the risk model developed and the results obtained.

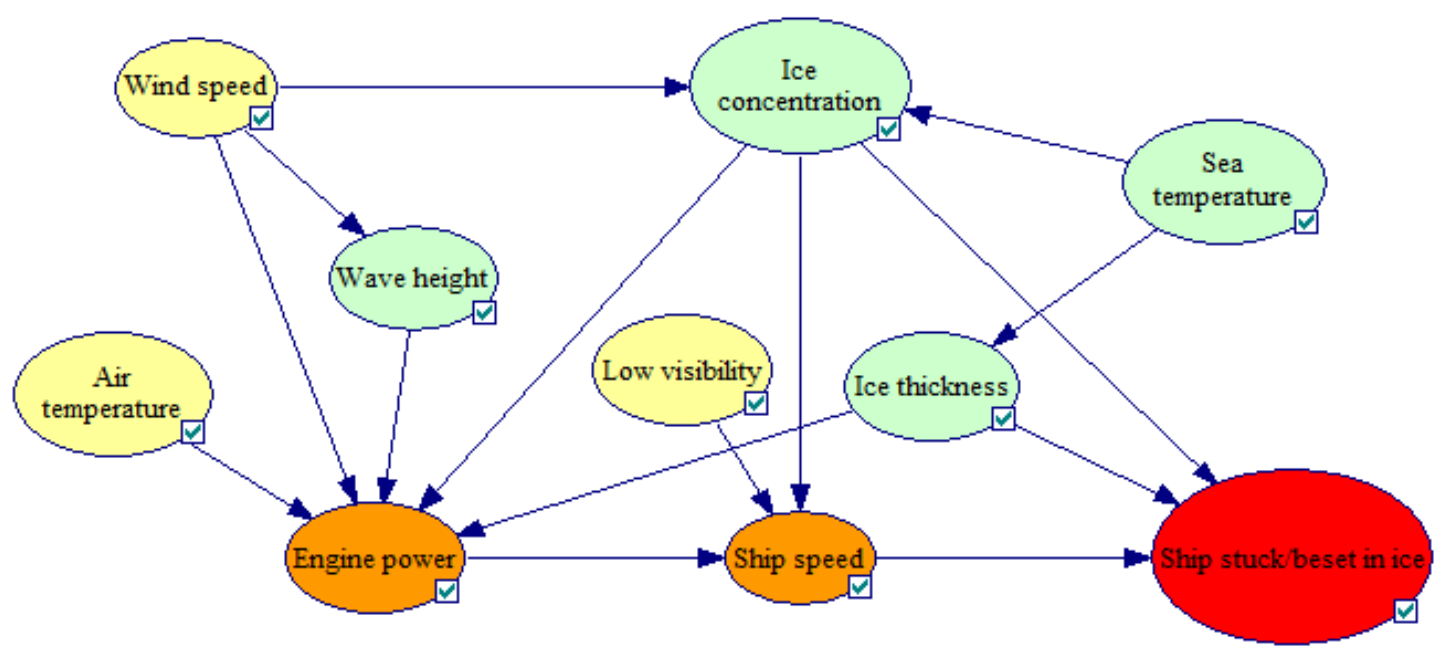

Fig. 5. The structure of a BBN model for predicting the probabilities of a ship stuck in ice. 


\subsubsection{Correlation analysis}

After selecting the set of model nodes, we ran correlation analysis to explore relationships between the nodes. The results of PMCC and the significance tests are presented in Table 3 and refer to the raw data as provided by COSCO shipping company.

\section{Table 3}

Pearson product-moment correlation coefficients of the selected risk influencing factors used to develop the structure of the BBN model) for estimating the probability of a ship besetting in in ice.

\begin{tabular}{ccccccccc}
\hline Name of RIF & No & \multicolumn{1}{c}{1} & \multicolumn{1}{c}{2} & 3 & 4 & 5 & 6 & 7 \\
\hline Ship speed & 1 & 1.000 & & & & & & \\
Engine power & 2 & $0.927^{* *}$ & 1.000 & & & & & \\
Wind speed & 3 & $0.421^{* *}$ & $0.389^{* *}$ & 1.000 & & & & \\
Air temperature & 4 & $0.345^{* *}$ & $0.551^{* *}$ & 0.033 & 1.000 & & & \\
Sea temperature & 5 & $0.459^{* *}$ & $0.595^{* *}$ & $0.331^{* *}$ & $0.591^{* *}$ & 1.000 & & \\
Ice concentration & 6 & $-0.650^{* *}$ & $-0.689^{* *}$ & $-0.522^{* *}$ & -0.141 & $-0.585^{* *}$ & 1.000 & \\
Wave height & 7 & $0.408^{* *}$ & $0.408^{* *}$ & $0.937^{* *}$ & 0.060 & $0.359^{* *}$ & $-0.550^{* *}$ & 1.000 \\
\hline
\end{tabular}

** Correlation is significant at the 0.01 level (2-tailed).

* Correlation is significant at the 0.05 level (2-tailed).

The records of the ice thickness parameter are based on visual observation from the ship's bridge. This parameter is estimated roughly and is represented by two categories (more or less than 0.5 meters). This parameter, along with the visibility, which remained at a constant level of 7 (good visibility) throughout the whole recording period, are removed from the correlation analysis. However, these two RIFs were still included in the BBN model due to their impacts on risk $[8,13,14,46,47]$.

\subsubsection{Direction of the arcs}

Ship stuck in ice is the output node of the model and it directly represents the probability of ship besetting in ice. The other parameters in the BBN structure act as both parent and child nodes, and are influenced by their associated parent node(s), and influence their associated child node(s), as presented in Table 4.

The PMCC results, as shown in Table 2, indicate that there are significant dependence relationships among RIFs. For example, engine power parameter has a positive or negative correlation with all the remainder RIFs in the Table 2 with PMCC exceeding |0.3|. We draw directed arcs from "wind speed", "air temperature", "ice concentration", "ice thickness" and "wave height" to "engine power", since engine power is the response variable for ship performance. Engine power is considered to determine the speed of a ship [8, 18], we draw discrete arc from "engine power" to "ship speed". Arcs between RIFs may be removed if they are part of the same response variables and the analyst determines that they have a weak causal relationship [32]. We omitted an arc between "sea temperature" and "engine power". The connection between "low visibility", "ice thickness" and "engine power" nodes was judged by causal logic and expert knowledge.

Likewise, we draw directed arcs from "ice concentration" and "low visibility" to "ship speed", from "wind speed" and "sea temperature" to "ice concentration", from "wind speed" to "wave height" and from "sea temperature" to "ice thickness" based on the results of PMCC analysis, casual relationships of the RIFs in the related works $[13,14,18]$ and expert judgment. Therein, "wind speed", "air temperature", "low visibility" and "sea temperature" can also be seem as root nodes that aren't influenced by any other nodes (RIFs).

\section{Table 4}

Direction of the arcs used in the BBN model for predicting the probability of a ship stuck in ice.

\begin{tabular}{cc}
\hline Child node & Parent node (s) \\
\hline Ship speed* & Engine power*, ice concentration, low visibility \\
Engine power* & Wind speed, air temperature, ice concentration, ice thickness, wave height
\end{tabular}


Ice concentration

Ice thickness

Wave height

Ship stuck in ice*
Wind speed, sea temperature

Sea temperature

Wind speed

*. Ship speed and engine are response variables that determine ship performance during voyage. Ship stuck in ice is a risk response variable that shows the probability of a ship stuck in ice.

\subsection{CPTs estimation}

This section presents CPTs for the proposed model. All the probabilities are conditional on one or more RIFs. Marginal probabilities for each RIF were determined from the 179 data points provided by COSCO during the voyage through the NSR. The marginal probability of each state $(\mathrm{k})$ of RIFs I was assessed using the relative frequency of the state for $\mathrm{n}$ sub-event [53], as follows:

$$
P\left(R I F_{i}=k\right)=\frac{n_{k}}{n} .
$$

For root nodes, the marginal probabilities fully specify the CPTs. The CPTs for the four root nodes are shown in Table 5. The marginal probability of "low visibility" S1 used to develop this table was set to $0 \%$ because there was not this evidence from the dataset to populate the CPTs based on the data, then it was set to $10 \%$ considering expert judgment.

Table 5

The CPTs for the three root nodes - wind speed, air temperature, low visibility and sea temperature.

\begin{tabular}{cccc}
\hline \multirow{2}{*}{ Node } & \multicolumn{3}{c}{ State } \\
\cline { 2 - 4 } & $S_{1}$ & $S_{2}$ & $S_{3}$ \\
\hline Wind speed & 0.15 & 0.74 & 0.11 \\
Air temperature & 0.29 & 0.71 & \\
Low visibility & 0.10 & 0.90 & \\
Sea temperature & 0.42 & 0.58 \\
\hline
\end{tabular}

For nodes with one or two parent nodes, the conditional probabilities are assessed marginal probability of the child and each parent as Eq. (6), and the CPTs for these kind of parameters are wave height, sea temperature and ice concentration parameters in the proposed BBN model, as shown in Table 6 and Table 7. However, the data cannot be always sufficient for populate CPTs for all the nodes, therefore the expert judgment is needed. For example, the marginal probability of ice concentration ( wind speed $=S_{l}$, sea temperature $=S_{3}$ ) used to develop this table was set to $25 \%$. There was no supporting evidence in the recorded data, but the experts provided their subjective probability of that particular state of a variable, based on their expertise and understanding of the analyzed system and the phenomenon under question.

\section{Table 6}

The CPTs for the wave height and sea temperature parameters.

\begin{tabular}{ccccc}
\hline & \multicolumn{3}{c}{ Wind speed } \\
\cline { 2 - 5 } & $S_{1}$ & $S_{2}$ & $S_{3}$ \\
\hline Wave height & $S_{1}$ & 0.78 & 0.00 & 0.00 \\
& $S_{2}$ & 0.22 & 1.00 & 0.00 \\
& $S_{3}$ & 0.00 & 0.00 & 1.00 \\
& & \multicolumn{4}{c}{ Ice thickness }
\end{tabular}




\begin{tabular}{cccc} 
& & $S_{1}$ & $S_{2}$ \\
Sea temperature & $S_{1}$ & 0.74 & 1 \\
& $S_{2}$ & 0.26 & 0 \\
\hline
\end{tabular}

Table 7

The CPT for the ice concentration parameter.

\begin{tabular}{cccccccc}
\hline & Sea temperature & \multicolumn{3}{c}{$S_{1}$} & & \multicolumn{3}{c}{$S_{2}$} \\
\cline { 2 - 8 } & Wind speed & $S_{1}$ & $S_{2}$ & $S_{3}$ & $S_{1}$ & $S_{2}$ & $S_{3}$ \\
\hline \multirow{3}{*}{ Ice } & $S_{1}$ & 0.05 & 0.16 & 0.60 & 0.56 & 0.67 & 1.00 \\
concentration & $S_{2}$ & 0.22 & 0.60 & 0.30 & 0.44 & 0.33 & 0.00 \\
& $S_{3}$ & 0.17 & 0.22 & 0.10 & 0.00 & 0.00 & 0.00 \\
& $S_{4}$ & 0.56 & 0.02 & 0.00 & 0.00 & 0.00 & 0.00 \\
\hline
\end{tabular}

The CPT for "engine power" has 288 columns, but it cannot be calculated using the Eq. (6) because there are not enough entries to cover all possible combinations of input parameters. Likewise, CPTs for the "ship speed" and "ship stuck in ice" have 32 columns respective because of the number of parent nodes and correspond states. The CPTs for these three nodes could be populated through use of expert judgment. Since the current BBN model is based on correlation analysis, the CPT for "engine power" is partial assessed using expert judgment. If additional data are available, the CPT can be calculated as Eq. (6).

After obtaining the CPTs for the parameters in the BBN model, the marginal probabilities for the ten nodes are calculated according to Eq. (4) and Eq. (5), as shown in Fig. 6.

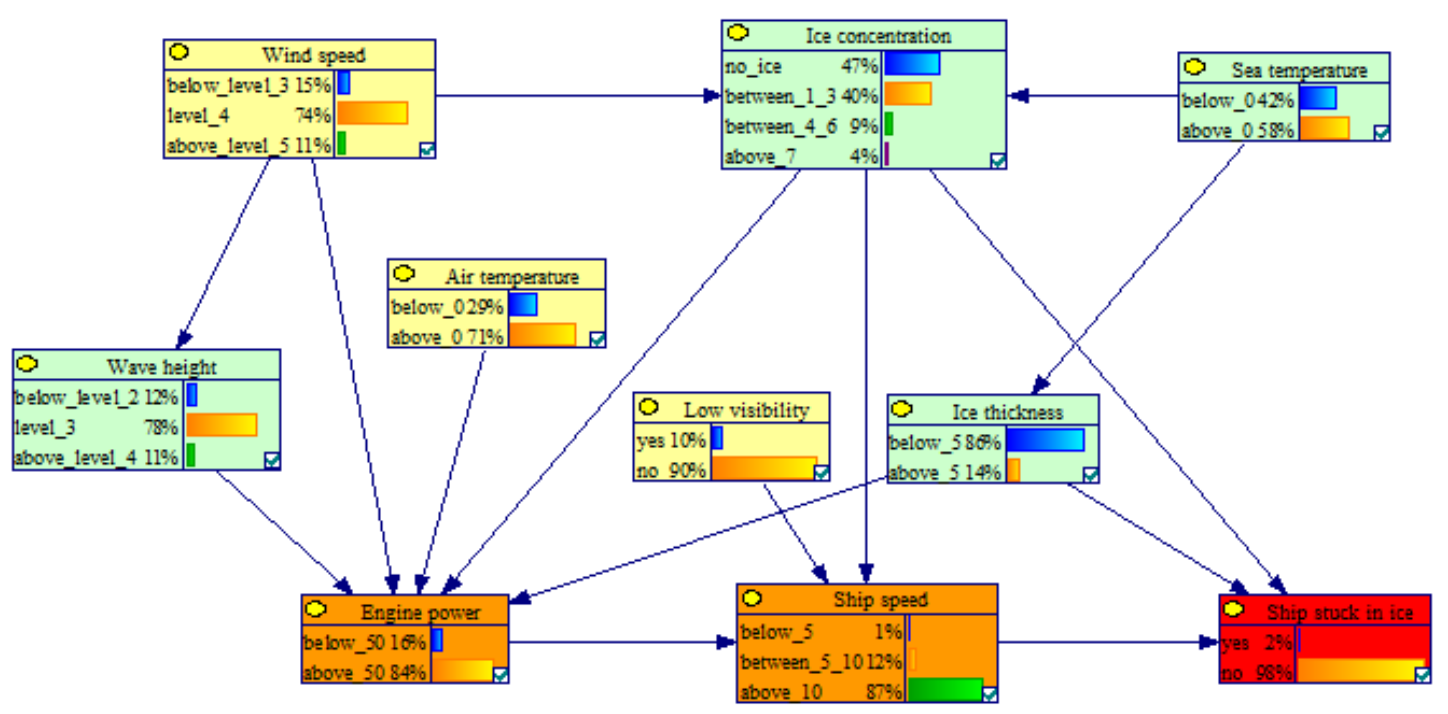

Fig. 6. Marginal probabilities for the BBN model.

\section{Model validation}

Validation is an important aspect of any modeling methodology, as it provides a reasonable amount of confidence in the results that are produced. In this section, the BBN model developed has been validated via a behavior sensitivity analysis and a framework proposed by Pitchforth and Mengersen [54]. The framework is found suitable for models developed with the use of expert judgment, allowing for both qualitative and quantitative assessment of the model.

\subsection{Sensitivity analysis}

A useful means to examine the validity of an expert-built model is to perform sensitivity analysis, whereby it 
is possible to graphically analyzed the greatest impact of a set of variables on a selected (target) node [55]. A behavior sensitivity test is used to assess to what model parameters the results are sensitive. The parameter sensitivity of a BN can be calculated and the results can be evaluated by domain experts. A parameter sensitivity analysis (PSA) is carried out to show how sensitive the results of a belief update (propagation of evidence) are to variations in the value of a parameter of the model. The values of the parameters of the model are the entries of the CPTs [56].

In this study, the PSA is based on the observation that the probability of the evidence is a linear function of any single parameter in the model. Let $\mathrm{A}$ be a node undergoing the sensitivity analysis and $a_{1}, a_{2}, \ldots, a_{n}$ be the $\mathrm{n}$ states of A. For a given evidence $\varepsilon$, the probability of the $i_{t h}$ state is $P\left(A=a_{i} \mid \varepsilon\right)$. Let $\mathrm{B}$ be an influencing node in the $\mathrm{BN}$ and let $x$ be a conditional probability parameter associated with state $\mathrm{b}$ of $\mathrm{B}$. Then, $\mathrm{P}\left(\mathrm{A}=a_{i} \mid \varepsilon\right)$ can be expressed as a linear function of $x$ :

$$
f(x)=P\left(A=a_{i} \mid \varepsilon\right)(x)=\alpha_{i} x+\beta_{j},
$$

where $\alpha_{i}$ and $\beta_{j}$ are real constants representing the slope and the intercept of the linear function, respectively. The sensitivity value of the $i_{t h}$ state of A with respect to state $\mathrm{b}$ of $\mathrm{B}$ is computed based on the following function:

$$
S_{A}=f^{\prime}(x)=\alpha_{i}
$$

Extending the consideration of a single state $\alpha_{i}$, the average sensitivity value of node $\mathrm{A}$ with respect to state $\mathrm{b}$ of $\mathrm{B}$ is calculated in order to illustrate its overall sensitivity, using the following equation:

$$
S_{A}=\frac{\sum_{i=1}^{n}\left|\alpha_{i}\right|}{n} .
$$

The PSA is, then, studied to analyze the impacts of the response variables "engine power", "ship speed" and "ship stuck in ice". According Eq. (7) (9), the results for the maximum absolute sensitivity values and corresponding parameters are presented in Table 8 10, when set these three responses variables as the target sensitivity variables.

\section{Table 8}

Maximum absolute sensitivity values for the variables and corresponding parameters in the BBN of Fig. 5, when "engine power" is set as the target (output) variable.

\begin{tabular}{ccc}
\hline Ranking & Variable & Sensitivity value \\
\hline 1 & Air temperature & 0.212 \\
2 & Wind speed & 0.192 \\
3 & Sea temperature & 0.183 \\
4 & Ice concentration & 0.093 \\
5 & Ice thickness & 0.025 \\
6 & Wave height & 0.009 \\
\hline
\end{tabular}

Table 9

Maximum absolute sensitivity values for the variables and corresponding parameters in the BBN of Fig. 5, when "ship speed" is set as the target (output) variable.

\begin{tabular}{ccc}
\hline Ranking & Variable & Sensitivity value \\
\hline 1 & Sea temperature & 0.231 \\
2 & Wind speed & 0.199 \\
3 & Ice concentration & 0.161 \\
4 & Air temperature & 0.114 \\
5 & Ice thickness & 0.090 \\
6 & Engine power & 0.062 \\
7 & Low visibility & 0.036 \\
8 & Wave height & 0.007 \\
\hline
\end{tabular}


Table 10

Maximum absolute sensitivity values for the variables and corresponding parameters in the BBN of Fig. 5, when "ship stuck in ice" is set as the target (output) variable.

\begin{tabular}{ccc}
\hline Ranking & Variable & Sensitivity value \\
\hline 1 & Ice concentration & 0.084 \\
2 & Wind speed & 0.064 \\
3 & Sea temperature & 0.045 \\
4 & Ice thickness & 0.024 \\
5 & Ship speed & 0.010 \\
6 & Low visibility & 0.006 \\
7 & Engine power & 0.004 \\
8 & Air temperature & 0.003 \\
9 & Wave height & 0.000 \\
\hline
\end{tabular}

From Table 8, it is obvious that the hydro-meteorology indicators ("air temperature", "wind speed" and "sea temperature") tend to be the most important parameters to "engine power" for the maximum sensitivity value, when when "engine power" is set as the target (output) variable, followed by the marine hydrology indicators such as "sea temperature", "ice concentration" and "ice thickness", and "wave height" also contributes to the variations in the value of "engine power", to a 0.001 precision. Likewise, from Table 9, it is obvious that the "sea temperature", "wind speed" and "ice concentration" tend to be the most important parameters for the maximum sensitivity values, when "ship speed" is set as the target (output) variable, followed by "air temperature", "ice thickness", "engine power" and "low visibility", and "wave height" also contributes to the variations in the value of "ship speed", to a 0.001 precision. From Table 10, it is evident that "ice concentration", "wind speed" and "sea temperature" tend to be the most important parameters for the maximum sensitivity value, when "ship stuck in ice" is set as the target (output) variable, followed by "ice thickness" and "ship speed"; "low visibility", "engine power", "air temperature" also contribute to the probability of a ship stuck in ice, to a 0.001 precision; but "wave height" seems to have limited impact on the probability of a ship stuck in ice for the corresponding maximum sensitivity value less than 0.001 . These indicate that all the environmental indicators are sensitive to the response variables ("engine power", "ship speed" and "ship stuck in ice") that can be seems as safety critical factors (SCFs) to probability of a ship stuck in ice-covered waters. Although "wave height" shows a limited impact on the probability of "ship stuck in ice", it contributes to the variations in the values of "engine power" and "ship speed".

The visual results of the sensitivity analysis related to the model parameters (conditional state probabilities) are presented in Fig. 7, when "ship stuck in ice=yes" in the full parameter range $([0,1])$. From a purely visual inspection for Fig. 7, we can think of the length of the bars in the tornado graphs as being the measure of the impact of that conditional state on ship stuck in ice. Fig. 7 illustrates the impacts of a set of greatest important model parameters (conditional states) including "ice concentration $=S 4 \mid$ sea temperature $=S 1$, wind speed=S2", "wind speed $=S 1 ", "$ sea temperature $=S 1 ", "$ wind speed $=S 2 "$, "ice concentration=S3| sea temperature $=S 1$, wind speed $=S 2 ", "$ ice thickness $=S 1 \mid$ sea temperature $=S 1 ", "$ "ice concentration $=S 1 \mid$ sea temperature $=S 1$, wind speed=S2", "ship stuck in ice=yes| ice thickness=S1, ship speed=S2, ice concentration=S3", "wind speed=S3" and "ice concentration $=S 4 \mid$ sea temperature $=S 1$, wind speed $=S 3$ " when "ship stuck in ice=yes". From Fig. 7, it is obvious that "wind speed", "sea temperature", "ice concentration" and "ice thickness" have impacts on "ship stuck in ice", which is accordance to the results presented in Table 10.

Moreover, green and red bars in tornado graph (Fig. 7) refer to positive and negative contributions to the target variables (ship stuck in ice) when "ship stuck in ice=yes". For example, "ice concentration= S4| sea temperature $=S 1$, wind speed=S2", "wind speed=S1", "wind speed $=S 1$ " and "sea temperature=S1" make a positive contribution to "ship stuck in ice=yes", which implies that the higher/lower conditional probability of these 
conditional states the higher/lower probability of a ship stuck in ice; likewise, "wind speed $=S 3$ " makes a positive contribution to "ship stuck in ice=yes", which implies that the higher/lower conditional probability of these conditional states the lower/higher probability of a ship stuck in ice.

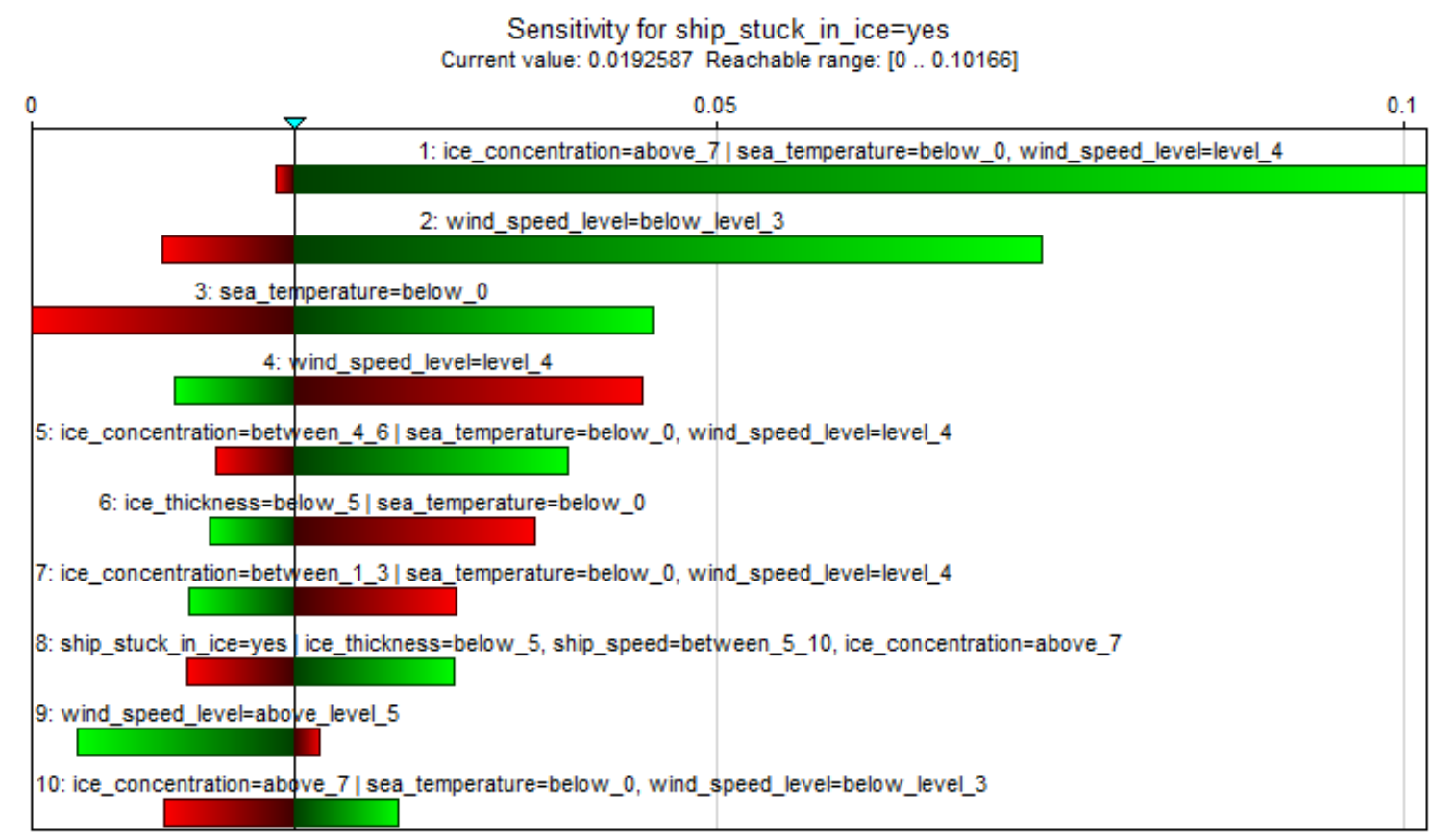

Fig. 7. Tornado graph depicting the ten top-ranked model parameters (conditional states) in the BBN model with output variable "ship stuck in ice $=$ yes".

\subsection{Framework for validation of BBN model}

The framework has been found useful for risk models, where there is a lack of reference data, and the model tends to capture complex relationships in a socio-technical system operating in dynamic environmental conditions, see for example [35,38].

The framework consists of several types of validity, some of which can be judged quantitatively, but the majority is of qualitative nature. Therefore, there is a need for a common grading scale for these validity types, to arrive at one and unambiguous conclusion regarding the validity of a BBN model. For that reason, the following qualitative scale is proposed to assess the adequacy of the risk models, with respect to each validity type:

- solid supporting evidence that a model performs well: good;

- some supporting evidence that a model performs well: moderate;

- little or no supporting evidence that a model performs well: poor.

The answers to the validation tests need to be justified, so the end-users of the risk model feel confident about it, and are aware of its limitations. Moreover, the results of validation indicate the areas of the model that need more investigation, which is informative to develop the model further. The framework is outlined below along with the results obtained, as shown in Fig. 8. 


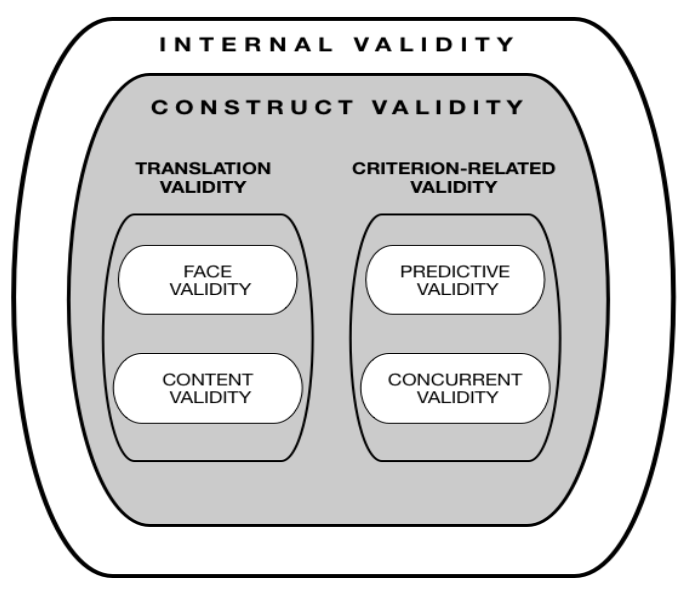

Fig. 8. A validation framework for BBN models.

In the framework, internal validity is the approximate truth about inferences regarding cause-effect or causal relationships. This type of validity is relevant in studies that try to establish a causal relationship. The key question in internal validity is whether observed changes can be attributed to intervention (i.e., the cause) and not to other possible causes (sometimes described as "alternative explanations" for the outcome). It reflects the extent to which a causal conclusion based on a study is warranted. Once the internal validity is established, and the structure of the model is developed, construct validity can be judged. For this purpose, construct validity is applied, which refers to how well the analyst translates a concept or an idea - that is a construct - into a functioning and operating reality that is the operationalization. Construct validity comprises four types of validity: face and content, which are grouped into translation validity, and predictive and concurrent, fitting under the umbrella of criterion validity, as depicted in Fig. 8.

Translation validity focuses on whether the operationalization reflects the true meaning of the construct. It attempts to assess the degree to which constructs are accurately translated into the operationalization, using subjective judgment - face validity - and examining content domain - content validity.

- Face validity is a subjective judgment on the operationalization of a construct. In other words, this type of validity checks whether or not the model that is validated captures the phenomenon it is intended to capture. It is commonly accepted, that this is a crude and basic measure of validity.

- Content validity is a more detailed comparison of the included variables in the BBN to those believed or known to be relevant in the real system.

Criterion-related validity measures the degree of correspondence between a test measure and one or more external, so called "objective" criteria. The "objective" results are obtained either by a well-established instrument ("the gold standard") or by direct measurement. The criterion-related validity may be quantified by the correlation coefficient between the two sets of measurements. Depending on the nature of the reference dataset, the criterion-related validity measures are subdivided into concurrent validity and predictive validity.

- Predictive validity refers to the ability of a model to estimate some event or outcome in the future. A number of specific tests (e.g. qualitative features test, behavior sensitivity test) can be performed on a model, to evaluate whether the model adequately meets certain criteria. In a qualitative feature test, the model response is evaluated for a number of test conditions in terms of a qualitative understanding of how the system is believed to respond under these conditions. 
- Concurrent validity evaluates how well a model that we validate or its part corresponds to a nomologically proximate model or part of it.

\subsection{Framework application}

In the framework application, we focus on the four basic validity types in the framework - face, content, predictive and concurrent validity. The qualitative rating of the validity of each type are judged, and the results are presented in Table 11.

Table 11

Qualitative ratings of the validity types comprised in the validation framework.

\begin{tabular}{|c|c|c|}
\hline Validity type & Qualitative rating & Explanation \\
\hline Internal & Moderate-good & $\begin{array}{l}\text { Since the causality is a fundamental premise of the risk model developed here, this type of } \\
\text { validity test is of high importance. The experts involved in the process of risk model } \\
\text { development and the available literature, however scarce, allows us to judge this type of } \\
\text { validity as moderate-good. }\end{array}$ \\
\hline Construct & Moderate-good & $\begin{array}{l}\text { The further decomposed validity concepts (translation and criterion-related) are assessed } \\
\text { as moderate and moderate-good, respectively. }\end{array}$ \\
\hline Translation & Moderate & $\begin{array}{l}\text { The further decomposed validity concepts (face and content) are assessed as } \\
\text { moderate-good and poor-moderate, respectively. }\end{array}$ \\
\hline Criterion-related & Moderate-good & The further decomposed validity concept (predictive and concurrent) are assessed as good. \\
\hline Face & Moderate-good & $\begin{array}{l}\text { The presented BBN model can be considered an appropriate model for predicting } \\
\text { probability of a ship stuck in ice, which was established based on the ship performance } \\
\text { model by Montewka et al }[13,14] \text {, the results of correlation analysis and some related } \\
\text { works by Fu et al [18] and Kfan et al [19]. Moreover, the structure of the BBN model was } \\
\text { modified and pursued by requesting confirmation and agreement from the participating } \\
\text { experts. Since there is a general agreement between experts, supported by available } \\
\text { literature on the structure of the proposed model, face validity can be judged between good } \\
\text { and moderate. }\end{array}$ \\
\hline Content & Poor-moderate & $\begin{array}{l}\text { The nodes in the BBN model have been selected based on the associated RIFs in the } \\
\text { relevant studies in Arctic waters [8,17-19], waterway transportation [57] and winter } \\
\text { navigation in Baltic sea [23,24]. Moreover, all the selected nodes (RIFs) are discretized } \\
\text { into several states, which cover the available data reasonably well. The remaining } \\
\text { hydro-meteorological conditions which may be observed along NSR, however were not } \\
\text { present in this particular voyage, are not included in the model. Neither, ice compression } \\
\text { nor icebergs are included in the model. This makes the validity score between poor and } \\
\text { moderate. }\end{array}$ \\
\hline Predictive & Good & $\begin{array}{l}\text { The BBN model shows good quantitative features and obvious sensitivity (see section } 5.1 \text { ) } \\
\text { for the target (output) risk variables "engine power", "ship speed" and "ship stuck in ice". } \\
\text { The output of the model behaves as expected when manipulating the input parameters. }\end{array}$ \\
\hline Concurrent & Good & $\begin{array}{l}\text { The presented model shares some features with other nomological adjacent models } \\
\text { presented in [21]. Since the models utilize different data sets (observation plus expert } \\
\text { judgment in the presented case and numerical ice model and AIS data in case of model } \\
\text { presented in [14]) the full compatibility of these models in terms of included parameters } \\
\text { and their discretization is not possible. Furthermore, the modeling technique adopted here } \\
\text { - BBN is recommended by the IMO [39] for maritime risk assessment, and has been } \\
\text { widely adopted in earlier studies [13,14,19,35,55]. }\end{array}$ \\
\hline
\end{tabular}

In the end, since both interval and construct validity are judged moderate-good in Table 11, the validity of the presented BBN model for predicting the probability of a ship stuck in ice is assessed to be moderated-good.

\section{Discussion}


The BBN model presented here features strong prediction power of the probability of ship stuck in ice. This obviously depends on three main elements: the model structure, model parameters and the parameters discretization method.

The model structure is constructed and determined based on the correlation analysis and expert judgement. However, it is difficult to verify the BBN model's structure using the limited objective data, so that we intend to conduct further studies and use confirmatory factor analysis methods such as structural equation modeling [58].

The model parameters are obtained from our earlier work [18], relevant literatures [8,13,14,17-24,46-49] and expert knowledge elicitation session. The modelling choice adopted allows us to combine these different types of data, so as to provide a valid risk model for the specific purpose. The values of the parameters can be obtained beforehand the ship is set to the seas, in order to estimate the associated risk, and if required adjust the route accordingly.

The parameters are discretized with the use of several discretization methods, depending on a parameter. Some parameters, like wind speed, ice concentration, ice thickness, are discretized according to a good seamen's practice as present onboard ships transiting the Arctic waters. However, with respect to continuous variables, it is an iterative and heuristic process. For example, the ship's speed variable has no clear division criterion and it is discretized based on its analysis of the time series of the ship's speed. Since the data discretization method may lead to different prediction results with respect to a given class of outcome variable, even if the model structure remains unchanged [14], we analyzed this effect in the presented model. The results of this analysis are very promising, since they show there are no significant changes in the outcome of the model, the probability of ship stuck in ice variable, based on the division into classes. This shows that the potential error stemming from the way how the variables are divided into classes can be considered marginal.

The proposed BBN model has been comprehensively verified via a validation framework. As a result, it shows good or moderate-to-good results in all but one validity test. The model scores poor-to-moderate in content validity tests, which is mainly due to the omission of some external factors that may be relevant to risk assessment of maritime transportation along Arctic waters. Some exemplary factors that are missing here are the presence of icebergs, multi-year ice floes or the visibility. These factors shall be included in the future model development research.

\section{Conclusion}

The aim of this paper is to develop a causal probabilistic model to predict the probability of a ship stuck in ice Arctic waters, given a set on input parameters describing the hydro-meteorological conditions along the analyzed route. Arctic navigation is relatively novel, compared to traditional navigation, and rather prospective topic. However, there is very limited historical data available to perform studies in the field or risk analysis for the Arctic Maritime Transportation System. To overcome this limitation, BBN modelling has been used and various available data sources from observation data information and expert judgment are integrated in one model. The results of the BBN model show quite strong agreement with the recorded data and common understanding of the Arctic shipping, which hopefully provides prior judgments for any ice-going ships before sailing in Arctic waters.

In this paper, RIFs for ice-covered Arctic waters are discussed; a full scale data for these risk indicators has been monitored and collected from Arctic voyages as a case study. The correlation analysis is applied to determine the structure of the nodes (RIFs) in the BBN model. The directions of the discredited arcs in the BBN model are judged in terms of logical relationships between nodes and expert judgment. Then, the completed BBN model is used to predict ship performances (ship speed and engine power) and the probability of a ship stuck in ice-covered 
Arctic waters. Furthermore, the established model is validated by behavior sensitivity analysis and a qualitative/quantitative validation framework, including internal, construct, translation, criterion-related, face, content, predictive and concurrent validity.

The identified and demonstrated SCFs for a ship stuck in ice-covered waters are significant to both onshore management and crews on board. The best conditions for safe Arctic transit can be evaluated by finding the conditional states for a ship stuck in ice to determine the lowest probability for this event. The model can also provide assistance to crews in avoiding conditions leading to the unwanted outcome.

Future work intends to consider more RIFs, i.e. the presence of icebergs and multi-year ice, or the effect of ice compression. Notwithstanding the limitations and simplifications of the risk model presented here, it is valid for its purpose (evaluating the probability of a ship stuck in ice in Arctic waters during certain season), and as such can be used by the ship operators.

\section{Acknowledgement}

This study was supported by the EU FP7 Marie Curie IRSES project "REFERENCE" (No. 314836) and National Science Foundation of China (NSFC) under grant No. 51579203.

The contributions by the third author are supported by the EU-funded project Vessel Operations and Routing in Ice Conditions (VORIC) funded by the Finnish Funding Agency for Innovation. The financial support is acknowledged. The opinions expressed are those of the authors and should not be construed to represent the views of the project consortia.

The presented Bayesian Network model has been developed using the GeNie modeling environment developed at the Decision Systems Laboratory, University of Pittsburgh, available from http://genie.sis.pitt.edu.

\section{References}

[1] V Verny, J., \& Grigentin, C. (2009). Container shipping on the northern sea route. International Journal of Production Economics, 122(1), 107-117.

[2] Ho, J. (2010). The implications of Arctic sea ice decline on shipping. Marine Policy, 34(3), 713-715.

[3] Parsons, J., Dinwoodie, J., \& Roe, M. (2011). Northern opportunities: A strategic review of Canada's Arctic icebreaking services. Marine policy,35(4), 549-556.

[4] Zhang Xia, Shou Jianmin, Zhou Haojie. (2013). The research on the scale and shipping cargo type of the Arctic waterway. Polar research, 2, 66-74.

[5] Schøyen, H., \& Bråthen, S. (2011). The Northern Sea Route versus the Suez Canal: cases from bulk shipping. Journal of Transport Geography, 19(4), 977-983.

[6] Northern Sea Route (NSR) information office. (2014, Dem. 19). http://www.arctic-lio.com/node/225.

[7] Zhao, Q. (2014). The ice-breaking journey pf MV "Yong Sheng" in the Arctic. China maritime safety, (9), 17-20.

[8] Maritime Safety Committee (MSC) (2014). International Code for Ships Operating in Polar Waters (Polar Code). https://edocs.imo.org/Final Documents/English/MEPC 68-21-ADD.1 (E).doc.

[9] Kotovirta, V., Jalonen, R., Axell, L., Riska, K., \& Berglund, R. (2009). A system for route optimization in ice-covered waters. Cold Regions Science and Technology, 55(1), 52-62.

[10] Kubat, I. (2012). Quantifying ice pressure conditions and predicting the risk of ship beset-ting. International Conference and Exhibition on Performance of Ships and Structures in Ice 2012 (ICETECH 2012).

[11] Kubat, I., Sayed, M., \& Babaei, M. H. (2013). Analysis of besetting incidents in Frobisher Bay during 2012 shipping season. In Proceedings of the International Conference on Port and Ocean Engineering Under Arctic Conditions.

[12] Kubat, I., Fowler, C.D., Sayed, M. (2015). Snow and ice-related hazards, risks and disasters. Elsevier, pp. 647 -676.

[13] Montewka, J., Sinclair, H., Kujala, P., Haapala, J., \& Lensu, M. (2013). Modelling ship performance in ice using Bayesian 
networks. In Proceedings of the International Conference on Port and Ocean Engineering Under Arctic Conditions.

[14] Montewka, J., Goerlandt, F., Kujala, P., \& Lensu, M. (2015). Towards probabilistic models for the prediction of a ship performance in dynamic ice. Cold Regions Science and Technology, 112, 14-28.

[15] Ehlers, S., \& Kujala, P. (2013). Optimization-based material parameter identification for the numerical simulation of sea ice in four-point bending. Proceedings of the Institution of Mechanical Engineers, Part M: Journal of Engineering for the Maritime Environment, 1475090213486892.

[16] Suominen, M., \& Kujala, P. (2014). Variation in short-term ice-induced load amplitudes on a ship's hull and related probability distributions. Cold Regions Science and Technology, 106, 131-140.

[17] Transport Canada. Arctic ice regime shipping system (1988). User assistance package for the implementation of Canada's Arctic ice regime shipping system (AIRSS).

[18] Fu, S., Zhang, D., Yan, X., Shi, J., Xu, L. (2015). Risk factors analysis of Arctic maritime transportation system using structural equation modeling. Proceedings of the 23rd international conference on Port and Ocean Engineering under Arctic Conditions. June 14-18, 2015, Trondheim, Norway.

[19] Khan, F., Yang, M., Veitch, B., Ehlers, S., \& Chai, S. (2014). Transportation Risk Analysis Framework for Arctic Waters. In ASME 2014 33rd International Conference on Ocean, Offshore and Arctic Engineering (pp. V010T07A018-V010T07A018). American Society of Mechanical Engineers.

[20] Kum S., Sahin B. (2015). A root cause analysis for Arctic Marine accidents from 1993 to 2011. Safety science, 2015, 74: 206-220.

[21] Marken, V. B., Ehlers, S., \& Khan, F. (2015). Delay risk analysis of ship sailing the northern sea route. Ship Technology Research-Schiffstechnik, 62(1), 26-35.

[22] Afenyo, M., Veitch, B., \& Khan, F. (2015). A state-of-the-art review of fate and transport of oil spills in open and ice-covered water. Ocean Engineering.

[23] Banda, O. A. V., Goerlandt, F., Montewka, J., \& Kujala, P. (2015). A risk analysis of winter navigation in Finnish sea areas. Accident Analysis \& Prevention, 79, 100-116.

[24] Goerlandt, F., Montewka, J., Zhang, W., \& Kujala, P. (2016). An analysis of ship escort and convoy operations in ice conditions. Safety Science, Paper accepted. doi:10.1016/j.ssci.2016.01.004.

[25] Valdez Banda, O. A., Goerlandt, F., Kuzmin, V., Kujala, P., \& Montewka, J. (2016). Risk Management Model of Winter Navigation Operations. Marine Pollution Bulletin. doi: org.10.1016/j.marpolbul.2016.03.071.

[26] Zio, E., \& Aven, T. (2011). Uncertainties in smart grids behavior and modeling: What are the risks and vulnerabilities? How to analyze them? Energy Policy, 39(10), 6308-6320.

[27] Zio, E., \& Aven, T. (2013). Industrial disasters: Extreme events, extremely rare. Some reflections on the treatment of uncertainties in the assessment of the associated risks. Process Safety and Environmental Protection, 91(1), 31-45.

[28] Nadkarni, S., \& Shenoy, P. P. (2001). A Bayesian network approach to making inferences in causal maps. European Journal of Operational Research, 128(3), 479-498.

[29] Modarres M., Kaminskiy M., \& Krivtsov V. (1999). Reliability engineering and risk analysis: a principle guide. Boca Raton, FL: CRC Press.

[30] Ren, J., Jenkinson, I., Wang, J., Xu, D. L., \& Yang, J. B. (2008). A methodology to model causal relationships on offshore safety assessment focusing on human and organizational factors. Journal of Safety Research, 39(1), 87-100.

[31] Ren, J., Jenkinson, I., Wang, J., Xu, D. L., \& Yang, J. B. (2009). An offshore risk analysis method using fuzzy Bayesian network. Journal of Offshore Mechanics and Arctic Engineering, 131(4), 041101.

[32] Groth, K. M., \& Mosleh, A. (2012). Deriving causal Bayesian networks from human reliability analysis data: A methodology and example model. Proceedings of the Institution of Mechanical Engineers, Part O: Journal of Risk and Reliability, 226(4), 361-379.

[33] Trucco, P., Cagno, E., Ruggeri, F., \& Grande, O. (2008). A Bayesian Belief Network modelling of organisational factors in risk analysis: A case study in maritime transportation. Reliability Engineering \& System Safety, 93(6), 845-856. 
[34] Zhang, D., Yan, X. P., Yang, Z. L., Wall, A., \& Wang, J. (2013). Incorporation of formal safety assessment and Bayesian network in navigational risk estimation of the Yangtze River. Reliability Engineering \& System Safety, 118, 93-105.

[35] Goerlandt, F., \& Montewka, J. (2014). A probabilistic model for accidental cargo oil outflow from product tankers in a ship-ship collision. Marine pollution bulletin, 79(1), 130-144.

[36] Chen, H., \& Moan, T. (2004). Probabilistic modeling and evaluation of collision between shuttle tanker and FPSO in tandem offloading. Reliability Engineering \& System Safety, 84(2), 169-186.

[37] Eleye - Datubo, A. G., Wall, A., Saajedi, A., \& Wang, J. (2006). Enabling a powerful marine and offshore decision - support solution through Bayesian network technique. Risk Analysis, 26(3), 695-721.

[38] Hänninen, M., Banda, O. A. V., \& Kujala, P. (2014). Bayesian network model of maritime safety management. Expert Systems with Applications, 41(17), 7837-7846.

[39] Maritime Safety Committee (MSC) (2013). Revised guidelines for formal safety assessment (FSA) for use in the rule-making process. MSC-MEPC.2/Circ.12. https://imo.amsa.gov.au/secure/circulars/msc-mepc2/12.pdf.

[40] Freedman, D. A., Collier, D., Sekhon, J. S., \& Stark, P. B. (2010). Statistical models and causal inference: a dialogue with the social sciences. Cambridge University Press.

[41] Kołowrocki, K., \& Kwiatuszewska-Sarnecka, B. (2008). Reliability and risk analysis of large systems with ageing components. Reliability Engineering \& System Safety, 93(12), 1821-1829.

[42] Kolowrocki, K. (2014). Reliability of Large and Complex Systems. Elsevier. ISBN: 978-0-08-099949-4.

[43] Thompson, B. (2004). Exploratory and confirmatory factor analysis: Understanding concepts and applications. American Psychological Association.

[44] Trucco, P., Cagno, E., Ruggeri, F., \& Grande, O. (2008). A Bayesian Belief Network modelling of organisational factors in risk analysis: A case study in maritime transportation. Reliability Engineering \& System Safety, 93(6), 845-856.

[45] Garvey, M. D., Carnovale, S., \& Yeniyurt, S. (2015). An analytical framework for supply network risk propagation: A Bayesian network approach. European Journal of Operational Research, 243(2), 618-627.

[46] Sørstrand, S. S. (2012). A Decision Support Model for Merchant Vessels Operating on the Arctic Sea. Master Thesis of Science degree in Marine, Technology at the Norwegian University of Science and Technology (NTNU).

[47] Ulstein, M. (2014). A simulation-based decision support tool for arctic field logistics. Master Thesis of Science degree in Marine, Technology at the Norwegian University of Science and Technology (NTNU).

[48] Schartmüller, B., Milaković, A. S., Bergström, M., \& Ehlers, S. (2015). A Simulation-Based Decision Support Tool for Arctic Transit Transport. In ASME 2015 34th International Conference on Ocean, Offshore and Arctic Engineering (pp. V008T07A006-V008T07A006). American Society of Mechanical Engineers.

[49] American Bureau of Shipping (ABS) (2014). Advisory: Navigating the Northern Sea Route - Status and Guidance.

[50] Grant, H. D. (1944). Cloud and weather atlas. Hugh Duncan Grant, Published by Coward, McCann.

[51] Douglas, B. (1991). Global sea level rise. Journal of Geophysical Research, 96(C4), 6981-6992.

[52] Maritime Safety Committee (MSC) (1995). RESOLUTION A.823(19).

[53] Bonafede, C. E., \& Giudici, P. (2007). Bayesian networks for enterprise risk assessment. Physica A: Statistical Mechanics and its Applications, 382(1), 22-28.

[54] Pitchforth, J., \& Mengersen, K. (2013). A proposed validation framework for expert elicited Bayesian Networks. Expert Systems with Applications, 40(1), 162-167.

[55] Hosseini, S., \& Barker, K. (2016). Modeling Infrastructure Resilience Using Bayesian Networks: A Case Study of Inland Waterway Ports. Computers \& Industrial Engineering.

[56] Kjaerulff, U. B., \& Madsen, A. L. (2008). Bayesian networks and influence diagrams. Springer Science+ Business Media, 200, 114.

[57] Zhang, D., Yan, X., Zhang, J., Yang, Z., \& Wang, J. (2016). Use of fuzzy rule-based evidential reasoning approach in the navigational risk assessment of inland waterway transportation systems. Safety Science, 82, 352-360. 
[58] Ullman, J. B., \& Bentler, P. M. (2003). Structural equation modeling. John Wiley \& Sons, Inc. 